\title{
Estimativa da produção de biogás e composição gravimétrica dos resíduos sólidos do município de Bom Sucesso-PB
}

\section{Estimation of biogas production and gravimetric composition of solid waste from the municipality of Bom Sucesso-PB}

Erick Ferreira de Sousa - Bacharel em Engenharia Ambiental e Sanitária, pela Universidade Federal Rural do Semi-Árido (UFERSA). Secretário de Administração e Planejamento na Prefeitura Municipal de Bom Sucesso-PB. E-mail: efdesousa94@gmail.com

Joel Medeiros Bezerra - Doutor em Engenharia Agrícola, pela Universidade Federal de Campina Grande (UFCG). Professor da Universidade Federal Rural do Semi-Árido (UFERSA). E-mail: joel.medeiros@ufersa.edu.br

Jessica Rafaelly Almeida Lopes - Mestranda em Engenharia Ambiental, na Universidade Federal Rural de Pernambuco (UFRPE). E-mail: jessicarafaellyalmeida@hotmail.com

\section{Resumo}

A disposição inadequada de resíduos resulta em danos ao ambiente, e riscos à saúde humana. No vazadouro de Bom Sucesso-PB ocorre a disposição inadequada e queima a céu aberto dos resíduos sólidos. Diante de tal panorama, buscou-se avaliar o vazadouro de Bom Sucesso-PB, por meio da composição gravimétrica, bem como estimativa da produção de biogás. Inicialmente foi realizado levantamento de campo mediante análise de composição gravimétrica, utilizando da técnica de quarteamento, para fins de contabilização das distintas frações de materiais, tal qual a estimativa das taxas de emissão do gás metano (CH4) pela fração orgânica. A composição gravimétrica do lixo possibilitou identificar uma predominância de material plástico, $30,6 \%$, um material reciclável dotado de valor econômico. A estimativa da geração de metano apontou valores pequenos se comparados a grandes cidades, porém vale salientar que a geração deste gás contribui para o agravamento do aquecimento global.

\section{Palavra-chave}

Descarte Inadequado. Degradação Ambiental. Vazadouro. Gravimetria.

\begin{abstract}
Improper waste disposal results in environmental degradation, and risks to human health. In Bom Sucesso-PB, there is inadequate disposal and open burning of solid waste. Given this scenario, we sought to evaluate the Bom Sucesso-PB drainage through gravimetric composition, as well as an estimation of biogas production. Initially, a field survey was undertaken by means of gravimetric composition analysis, using the quenching technique, to account for the different material fractions, such as estimation of methane gas (CH4) emission rates from the organic fraction. The gravimetric composition of the waste made it possible to identify the predominance of plastic material, 30.6\%, which is a recyclable material with economic value. The estimated methane generation showed small values compared to larger cities. However, it is worth noting that the generation of this gas contributes to the worsening of global warming.
\end{abstract}

\section{Keywords}

Inappropriate Disposal. Environmental Degradation. Landfill Site. Gravimetry. 


\section{INTRODUÇÃO}

Os Resíduos Sólidos Urbanos (RSU) apresentam uma composição diversa e têm origem em várias fontes, desde atividades domésticas residenciais e de serviços de varrição e limpeza pública (SANTIAGO; DIAS, 2012). Para Rezende et al. (2013), o consumo exagerado dos recursos naturais resulta em um grande crescimento na geração de RSU sendo estes compostos principalmente de matéria orgânica, recicláveis e rejeitos.

Segundo Campos (2012) e Godecke, Naime e Figueiredo (2012), a geração dos RSU está ligada a alguns fatores como aumento da população e concentração na área urbana, fatores econômicos, sociais, culturais e hábitos de vida. Por isso, os RSU requerem atenção especial devido à sua complexidade e volume crescente, sendo que a grande produção de rejeitos é um problema ambiental, além de ser um desafio para os municípios, pois demanda gestão, sendo esta complexa (SANTIAGO; DIAS, 2012).

De acordo com o Panorama dos Resíduos Sólidos no Brasil, em 2018 a geração de total de RSU no Brasil alcançou um montante de 216.629 t/dia, com uma geração per capita de 1,039 kg/hab./dia. Na região Nordeste a geração de resíduos chegou a 53.975 t/dia, dos quais $81,1 \%$, ou 43.763 t/dia, foram coletados, e os outros 18,9\%, ou $10.212 \mathrm{t} / \mathrm{dia}$, foram destinados para a coleta seletiva. Dos resíduos coletados, 31,5\% foram destinados a vazadouros a céu aberto, 32,9\% a aterros controlados e 35,6\% a aterros sanitários (ABRELPE, 2019).

A disposição ordenada de rejeitos em aterros é a forma de disposição final ambientalmente adequada prevista pela Política Nacional de Resíduos Sólidos (PNRS), porém para que chegue ao aterro somente o material que não pode mais ser reaproveitado se faz necessário que alguns processos sejam feitos como: reciclagem, reutilização, compostagem, recuperação e aproveitamento energético (BRASIL, 2010).

As formas de destinação final dos RSU podem ser: aterros sanitários, aterros controlados e os vazadouros (lixões) a céu aberto. Sendo o dispositivo do aterro sanitário a melhor forma de disposição de rejeitos no solo, sem trazer prejuízos à saúde pública e à segurança, além de minimizar os impactos ambientais. Para sua construção e funcionamento são utilizados princípios de engenharia para acomodar os resíduos numa menor área possível de forma compactada (ABNT, 1992). Corroborando com tais apontamentos, Gbanie et al. (2013) mencionam que os aterros são a forma correta de destinar os RSU, sendo necessário locar o aterro de forma apropriada com vistas a evitar custos socioeconômicos e ambientais. 
No que se refere à disposição final, os aterros sanitários receberam 59,5\% dos RSU coletados, representando 43,3 milhões de toneladas. Já os outros 40,5\%, ou seja, 29,5 milhões de toneladas, foram destinados a lixões e aterros controlados. Estes locais são considerados inadequados para destinação de RSU, uma vez que não possuem um conjunto de técnicas, sistemas e medidas de proteção contra a degradação ambiental e da saúde pública (ABRELPE, 2019).

Ao avaliar o cenário dos resíduos levados para aterros sanitários do ano de 2018 para 2016, verifica-se um retrocesso na disposição final dos resíduos. Dos 5.570 municípios brasileiros, 3.001, ou 54,51\%, ainda destinam seus resíduos para vazadouros a céu aberto, deste total, 816 ou 45,49\% municípios estão no Nordeste, tornando essa região a que possui maior número de cidades que adotam essa modalidade de disposição final (ABRELPE, 2019).

Os problemas ambientais advindos da destinação final inadequada são perceptíveis no semiárido brasileiro, a exemplo da cidade de Juazeiro do Norte-CE, onde Cordeiro et al. (2012) constataram que o percolado advindo do vazadouro contamina o solo e a decomposição da matéria orgânica elimina para a atmosfera gases nocivos, resultando em consequências adversas para os moradores do entorno. O município de Pau dos Ferros-RN também deposita seus resíduos em vazadouro a céu aberto que recebe, aproximadamente, $4 \mathrm{t} /$ dia. $\mathrm{Na}$ área do vazadouro percebe-se afloramento de chorume, presença de catadores, inexistência de isolamento físico e presença de animais (LUNES et al., 2016; SANTOS, 2016).

No estado da Paraíba, no ano de 2018, foram geradas 3.551 t/dia de RSU, sendo coletadas $85,66 \%$ ou $3.042 \mathrm{t} /$ dia. Deste total coletado, $943 \mathrm{t} /$ dia foram destinadas a aterros sanitários, $1.113 \mathrm{t} /$ dia a aterros controlados e $986 \mathrm{t} / \mathrm{dia}$ a lixões (ABRELPE, 2019). Algumas mudanças podem ser vistas no estado da Paraíba perante as propostas da PNRS, em cidades de maior porte, a exemplo de Campina Grande, no estado da Paraíba, que destinava os resíduos a um vazadouro presente no mesmo município, ocupando uma área de 35 hectares, e adequou-se, passando a destinar seus rejeitos para um aterro sanitário no município vizinho de Puxinanã/PB (ALVES et al., 2013). Cidades de menor porte também estão se adequando, a exemplo de Pedras de Fogo, que além de destinar seus resíduos ao aterro, ainda desenvolve políticas de coleta seletiva, e encaminha ao aterro somente o rejeito, aumentando assim sua vida útil (SENA et al., 2015).

O município de Bom Sucesso-PB deposita os RSU no próprio território, em um vazadouro a céu aberto, sem nenhum tratamento dos resíduos, ausente de coleta seletiva, ou compostagem (CNM, 2017). É notório que Bom Sucesso, a exemplo de outros municípios paraibanos, não se enquadra nas determinações legais da PNRS, necessitando, portanto, de adequações com finalidade de promover um gerenciamento ambiental efetivo e satisfatório dos RSU. 
A disposição em vazadouros atrai vetores de doenças, animais, seres humanos expostos a atividades de risco, além da geração de biogás e chorume (ALMEIDA et al., 2014). Diante deste contexto, buscou-se avaliar o cenário do vazadouro de Bom Sucesso-PB, por meio da determinação da composição gravimétrica dos resíduos sólidos urbanos dispostos no local, tal como a estimativa da produção de biogás pelo mesmo.

\section{METODOLOGIA}

\section{1 ÁREA DE ESTUDO}

O município de Bom Sucesso é um município brasileiro do estado da Paraíba (Figura 1), situa-se na Região Geográfica Imediata de Catolé do RochaSão Bento e Região Geográfica Intermediária de Patos. Faz fronteira ao norte com os municípios de Alexandria-RN e Brejo dos Santos-PB, a leste com Brejo dos Santos-PB e Jericó-PB, ao sul com Lagoa-PB e Santa Cruz-PB e a oeste com Alexandria-RN e Santa Cruz-PB (IBGE, 2017a).

Figura 1 - Localização do município de Bom Sucesso-PB

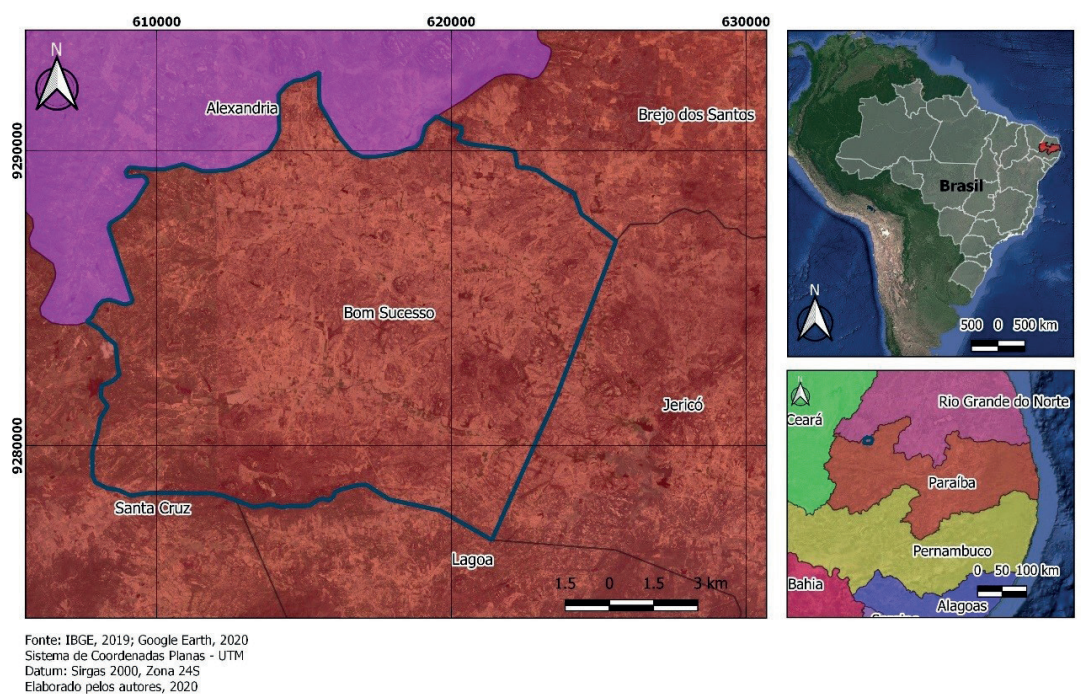

Fonte: Autores, 2020.

O município foi criado pela Lei no 3.049, de 17 de junho de 1963, e instalado em 02 de agosto de 1963. Bom Sucesso-PB possui uma área de 184,102 km² e uma população de 4.956 habitantes, de acordo com a estimativa para o ano de 2020, o que equivale a uma densidade demográfica de 26,92 hab. $/ \mathrm{km}^{2}$ (IBGE, 2020). 
O município deposita seus resíduos em um vazadouro a céu aberto (lixão), localizado em seus limites, estando situado nas proximidades da área urbana. $\mathrm{O}$ vazadouro iniciou sua operação desde 2001, conforme a Lei no 199/2001 que dispõe sobre a compra do terreno para implantação do vazadouro. O terreno adquirido pelo município para funcionamento do vazadouro possui as seguintes dimensões: $136 \mathrm{~m}$ ao norte, $89 \mathrm{~m}$ ao sul, 92,5 $\mathrm{m}$ a leste e $51 \mathrm{~m}$ a oeste.

O vazadouro recebe resíduos urbanos e da construção civil, além de restos de abates de animais. Ademais, tem uma vala para infiltrar efluentes advindos de fossa. A área não possui isolamento físico, aterramento dos resíduos, manta de drenagem subterrânea, captação e tratamento de chorume e biogás. Tem-se ainda a presença de um catador autônomo, que segrega e vende materiais recicláveis. A distância do vazadouro em relação ao centro da cidade de Bom Sucesso-PB é de aproximadamente $1,5 \mathrm{~km}$. Percebe-se a presença de corpos hídricos próximos à área do vazadouro e distantes aproximadamente $300 \mathrm{~m}$ (Figura 2).

Figura 2 - Localização do vazadouro (lixão) em relação à cidade de Bom Sucesso$\mathrm{PB}$ e aos corpos hídricos existentes

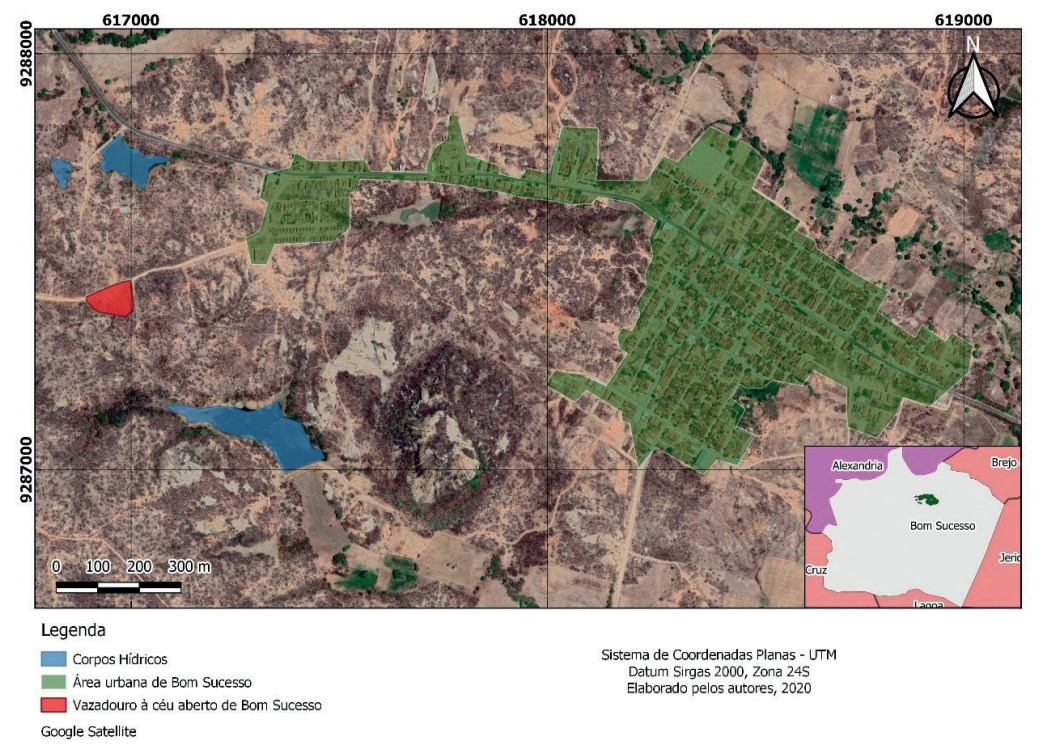

Fonte: Autores, 2020.

\subsection{PROCEDIMENTOS DE CAMPO}

Para fins de estudos de modelagem e projeção temporal foram utilizados os dados referentes ao ano de 2017, considerando que a composição gravimétrica foi realizada no referido ano. 
A determinação da composição dos resíduos sólidos foi realizada por meio de visitas in loco para fins de levantamento da composição gravimétrica, adotando-se procedimentos de quarteamento da amostra representativa (Figura 3), conforme proposto por Pessin, De Conto e Quissini (2002). Nesse método escolhe-se a procedência do veículo ou veículos coletores de acordo com critérios de representatividade. Os resíduos coletados são descarregados no solo. Procede-se então ao rompimento do maior número possível de sacos de resíduos, sendo coletadas quantidades em cinco pontos, uma no topo e quatro nas laterais do monte de resíduos. No presente estudo, para fins de otimizar a logística de amostragem, adaptou-se o volume coletado de modo a preencher cinco tonéis de 20 litros cada.

Figura 3 - Ilustração do procedimento de caracterização da amostra pelo método do quarteamento

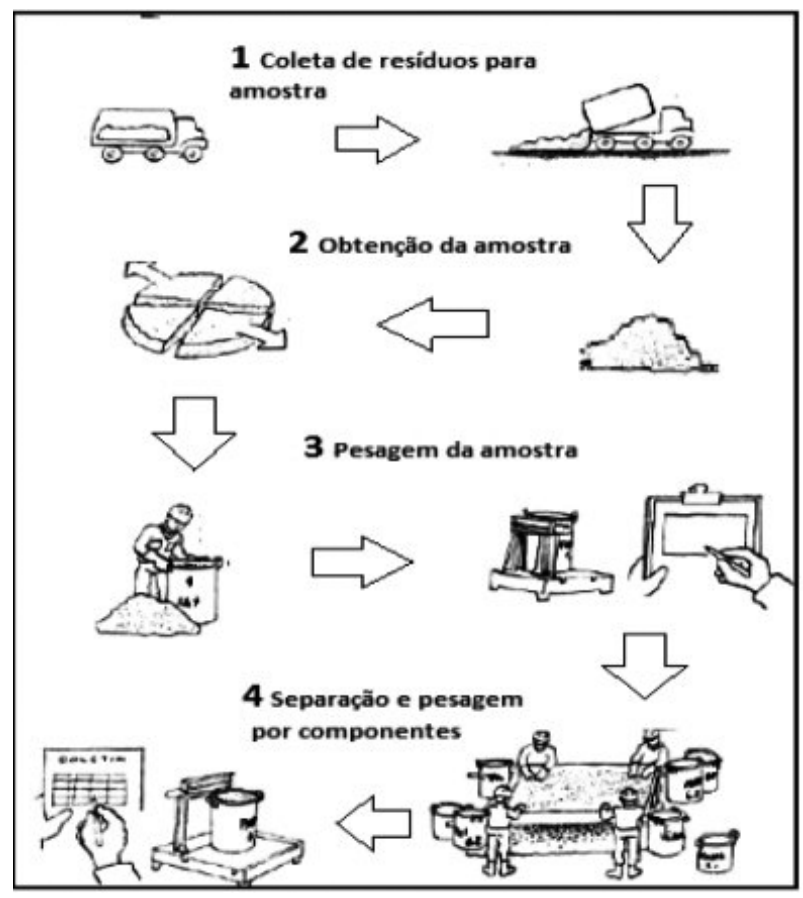

Fonte: Gasques (2013, p. 34).

Os tonéis preenchidos são despejados sobre uma lona plástica, iniciandose a mistura com revolvimento, seguido do quarteamento da amostra, ou seja, a divisão em quatro partes do total de 100 litros de resíduos dispostos. Duas das partes obtidas pelo quarteamento, e localizadas em posição diametralmente oposta são descartadas. 
O quarteamento foi realizado segundo a metodologia empregada por Lunes (2017) adaptada de Alkmin e Ribeiro Júnior (2017). Após a descarga do caminhão coletor, por volta das $10 \mathrm{~h}$ da manhã, foram separadas, por meio de um balde de 20 litros, 5 amostras de material de resíduos do montante despejado pelo caminhão compactador, sendo dispostas uma no topo e quatro na base da pilha de material, possibilitando promover maior representatividade, de modo a preencher cinco baldes de 20 litros cada.

O conteúdo dos baldes foi despejado sobre a lona plástica, iniciou-se a mistura e o quarteamento da amostra, ou seja, a divisão em quatro partes do total de 100 litros de resíduos dispostos. O montante de resíduo foi dividido em quatro partes iguais e, em seguida, eliminadas duas partes da diagonal oposta. Posteriormente foi feita a separação por tipologia de material e pesagem dos resíduos nas seguintes categorias: matéria orgânica (restos de alimentos), papel e papelão, plásticos, metal, vidro, rejeitos, tecidos, madeira e resíduos de parques e jardins.

Para este trabalho utilizaram-se os seguintes instrumentos: lona plástica, pá, enxada, sacos plásticos, balança e Equipamentos de Proteção Individual (EPI). As amostras coletadas foram depositadas sobre a lona plástica (Figura 4A e B), abertas e reviradas (Figura 4C e D), objetivando a homogeneização do material.

Figura 4 - Procedimentos metodológicos de quarteamento para análise da composição gravimétrica: A) e B) Disposição das amostras sobre a lona; C) Abertura dos sacos contendo material; D) Segregação dos materiais por tipologia

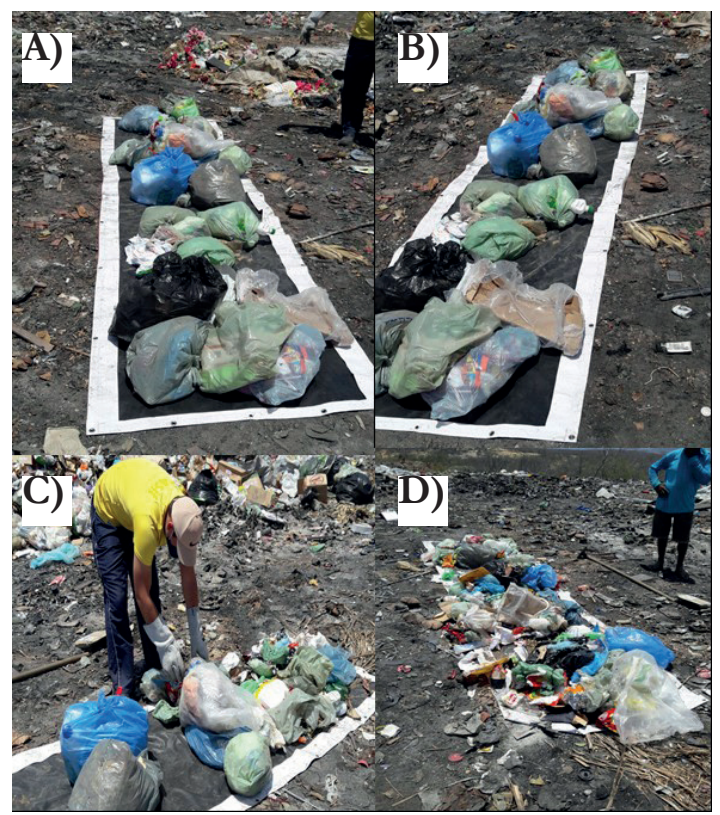

Fonte: Autores, 2020. 
Para fins de obtenção de informações sobre a estrutura do lixão, tais como os materiais descartados, realizou-se entrevista com o catador existente na área. Desta forma, possibilitou-se obter um contexto histórico da importância da área frente a suas adversidades.

\subsection{ESTIMATIVA DO BIOGÁS}

Para a estimativa do biogás gerado pela decomposição orgânica dos resíduos sólidos foi utilizada a metodologia proposta pelo Painel Intergovernamental sobre Mudanças Climáticas (IPCC, 1996), conforme Salvador (2012) e Souza (2013). Para estimar o biogás foi necessário aferir dados sobre o lixão como o total de resíduos dispostos na área, uma vez que este tipo de área degradada não dispõe de controle de entrada e saída de materiais.

O método envolve a estimativa da quantidade de carbono orgânico (CO) degradável presente nos RSU, calculando assim a quantidade de metano $\left(\mathrm{CH}_{4}\right)$ que pode ser gerada por determinada quantidade de resíduo depositado, considerando diferentes categorias de resíduos sólidos domésticos. Utilizou-se a Equação 1 para estimar a quantidade de metano gerado:

$$
\mathrm{Q}_{\mathrm{CH}_{4}}=\frac{\text { Pop urb } * \text { Taxa RSD } * \mathrm{RSDf} * \mathrm{~L}_{0}}{\rho \mathrm{CH}_{4}}
$$

Em que:

$\mathrm{Q}_{\mathrm{CH} 4}$ : metano gerado $\left[\mathrm{m}^{3} \mathrm{CH}_{4} /\right.$ ano $]$;

Pop urb: população urbana [habitantes];

Taxa RSD: taxa de geração de resíduos sólidos domiciliares por habitante por ano [kg de RSD/habitante/ano];

RSDf: fração de resíduos sólidos domésticos depositada em locais de disposição de resíduos sólidos [\%];

$\mathrm{L}_{0}$ : potencial de geração de metano do $\mathrm{RSU}\left[\mathrm{kg}\right.$ de $\mathrm{CH}_{4} / \mathrm{kg}$ de RSD]; $\varrho \mathrm{CH}_{4}$ : massa específica do metano $\left[\mathrm{kg} / \mathrm{m}^{3}\right]$.

O potencial de geração de metano $\mathrm{L}_{0}$ foi estimado por meio da composição dos resíduos. O valor do parâmetro $\mathrm{L}_{0}$ foi estimado pela Equação 2, que se baseia no conteúdo de carbono do resíduo, na fração de carbono biodegradável e num fator de conversão estequiométrico.

$$
\mathrm{L}_{0}=\mathrm{FCM} * \mathrm{COD} * \operatorname{CODf} *\left(\frac{16}{12}\right)
$$


Sendo:

$\mathrm{L}_{0}$ : potencial de geração de metano do lixo [ $\mathrm{kg}$ de $\mathrm{CH}_{4} / \mathrm{kg}$ de $\mathrm{RSD}$ ];

FCM: fator de correção de metano [\%];

COD: carbono orgânico degradável [kg de C/kg de RSD];

CODf: fração de COD dissociada [\%];

F: fração em volume de metano no biogás [\%];

(16/12): fator de conversão de carbono em metano $\left[\mathrm{kg}\right.$ de $\mathrm{CH}_{4} / \mathrm{kg}$ de C].

A Tabela 1 apresenta os valores para o parâmetro fator de correção do metano (FCM). Esse valor varia em função do local de disposição.

Tabela 1 - Valores para o parâmetro fator de correção do metano

\begin{tabular}{c|c}
\hline Tipo de local de disposição & FCM \\
\hline Lixão & 0,4 \\
Aterro controlado & 0,8 \\
Aterro sanitário & 1,0 \\
Locais sem categoria & 0,6 \\
\hline
\end{tabular}

Fonte: IPCC (1996, apud Salvador, 2012).

Para a obtenção do parâmetro COD foi utilizada a Equação 3, que se baseia na composição do RSU e no potencial de produção de carbono que cada componente apresenta (Tabela 2).

$$
\mathrm{COD}=(0,40 * \mathrm{~A})+(0,17 * \mathrm{~B})+(0,15 * \mathrm{C})+(0,40 * \mathrm{D})+(0,30 * \mathrm{E}) \quad \text { Eq. } 3
$$

Sendo:

COD: carbono orgânico degradável [kg de C/kg de RSD];

A: fração de papel e papelão no RSU;

B: fração de resíduos de parques e jardins no RSU;

C: fração de restos de alimentos no RSU;

D: fração de tecidos no RSU;

E: fração de madeira no RSU. 
Tabela 2 - Teor de carbono orgânico degradável para cada componente do lixo

\begin{tabular}{lc}
\hline \multicolumn{1}{c|}{ Componente } & Porcentagem de COD (em massa) \\
\hline Papel e papelão & 40 \\
Resíduos de parques e jardins & 17 \\
Restos de alimentos & 15 \\
Tecidos & 40 \\
Madeira & 30 \\
\hline
\end{tabular}

Fonte: IPCC (1996, apud SALVADOR, 2012).

Para obtenção do parâmetro da fração de carbono orgânico degradável (CODf) foi utilizada a Equação 4. O mesmo indica a fração de carbono que é disponível para a decomposição bioquímica.

$$
\operatorname{CODf}=\left(0,014^{*} \mathrm{~T}\right)+0,28
$$

Sendo:

CODf: fração de COD dissociada [\%];

T: temperatura na zona anaeróbia $\left[{ }^{\circ} \mathrm{C}\right]$.

\section{RESULTADOS E DISCUSSÃO}

\subsection{COMPOSIÇÃO GRAVIMÉTRICA}

O vazadouro de Bom Sucesso-PB está em funcionamento desde o ano de 2001, recebendo, de segunda a sexta-feira, os RSU do município, recolhidos por caminhão compactador, no período da manhã. Além dos RSU, outros rejeitos são destinados ao vazadouro, como: resíduos de abatedouros, construção civil, comércios, agrícolas, varrição pública, lixo eletrônico e lodo proveniente de limpeza de fossa, como se pode observar nos registros fotográficos obtidos mediante visita in loco (Figura 5). É notória a presença de animais, insetos, fedor e fumaça advinda da queima do lixo, o que confere ao local uma condição insalubre. Próximo à área do vazadouro encontram-se corpos hídricos lênticos (pequenos açudes). Como mostrada na figura 2 anteriormente. 
Figura 5 - Paisagem do vazadouro de Bom Sucesso-PB: A) Queima dos resíduos e dispersão de fumaça; B) Carcaça de animal, proveniente de resíduos de abatedouros; C) Presença de catador sem uso de EPI; D) Disposição de material no solo de forma inadequada e presença de corpo hídrico ao fundo da imagem

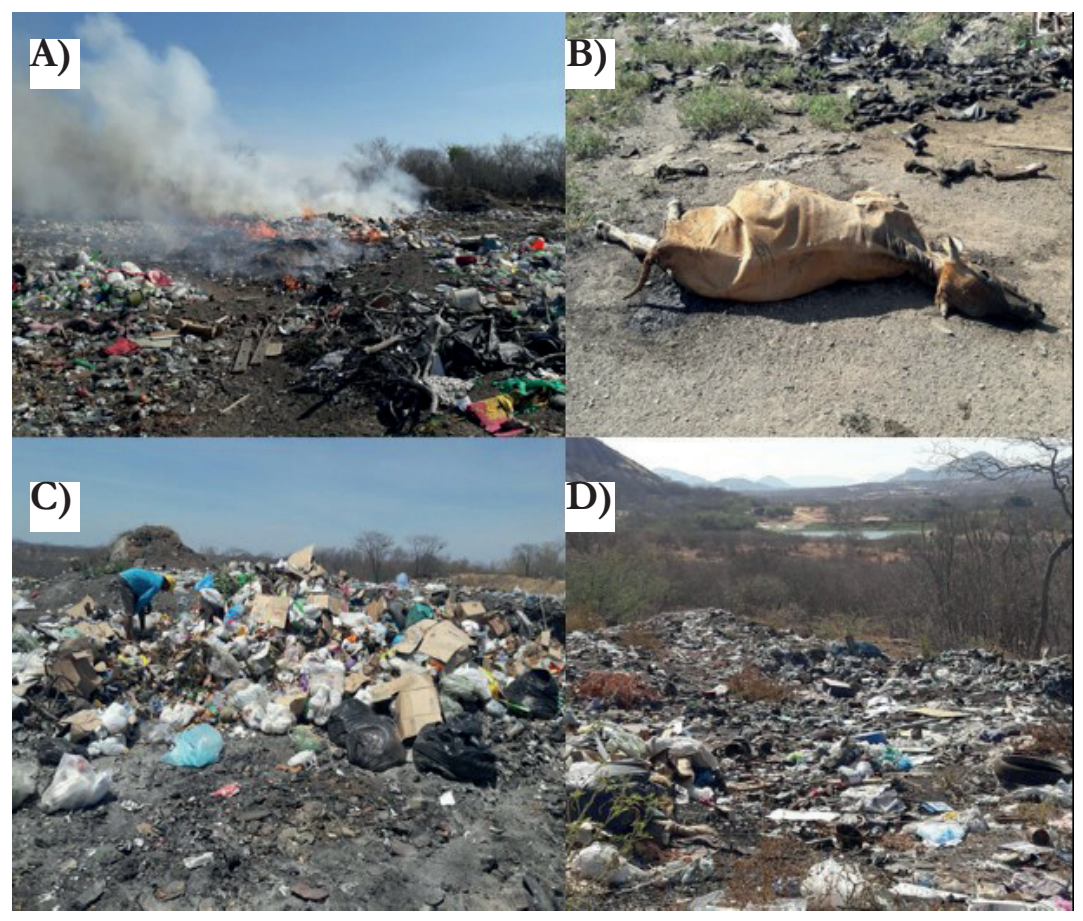

Fonte: Autores, 2020.

Tais circunstâncias promovem um cenário de risco aos distintos compartimentos do ambiente, pela possibilidade de contaminação, além da degradação existente, o que pode desencadear a ocorrência de ambiente propício à proliferação de vetores, tais como os riscos à saúde dos animais e à saúde dos trabalhadores, tendo em vista a condição insalubre. Estudos realizados por Cavalcante e Franco (2007) verificaram as condições insalubres em que se encontram os catadores autônomos que trabalham em vazadouros a céu aberto, uma vez que eles estão expostos aos agentes físicos, químicos e biológicos, além dos riscos ocupacionais a que estão sujeitos.

A cidade não possui coleta seletiva, porém existe um catador autônomo que faz a segregação entre recicláveis e rejeitos na área do vazadouro, sendo que todo material reciclado é vendido a atravessadores. Segundo informações fornecidas pelo catador, o mesmo recolhe mensalmente uma média de $1.000 \mathrm{~kg}$ de plástico, $5 \mathrm{~kg}$ de cobre, $50 \mathrm{~kg}$ de alumínio e $100 \mathrm{~kg}$ de melissa (sandálias de plástico). Tal 
fato pode ser justificado em função da inexistência da cultura de reciclagem entre seus habitantes, tal como a falta de uma coleta seletiva, favorecendo o acúmulo de tais materiais no vazadouro de disposição final. Assim, o único agente reciclador realiza a segregação na própria área de disposição.

Por meio da realização de prospecção com auxílio de trado holandês foi encontrado solo úmido em uma profundidade de $40 \mathrm{~cm}$, o que indica a presença de chorume infiltrado no solo, haja vista o período de estiagem de chuvas prolongado na localidade. Em contrapartida, a presença de embasamento rochoso faz com que parte do chorume não infiltre e seja carreado para áreas mais baixas.

Para a composição gravimétrica dos resíduos foram coletadas amostras de matéria orgânica, papel e papelão, plástico, metal, vidro, rejeitos, tecidos, madeira e resíduos de parques e jardins. A composição gravimétrica (Figura 6) apresentou um maior percentual de plástico, correspondendo a 30,96\% do montante, seguido de matéria orgânica, com 26,72\%.

Figura 6 - Composição gravimétrica dos RSU do município de Bom Sucesso-PB, em 2017

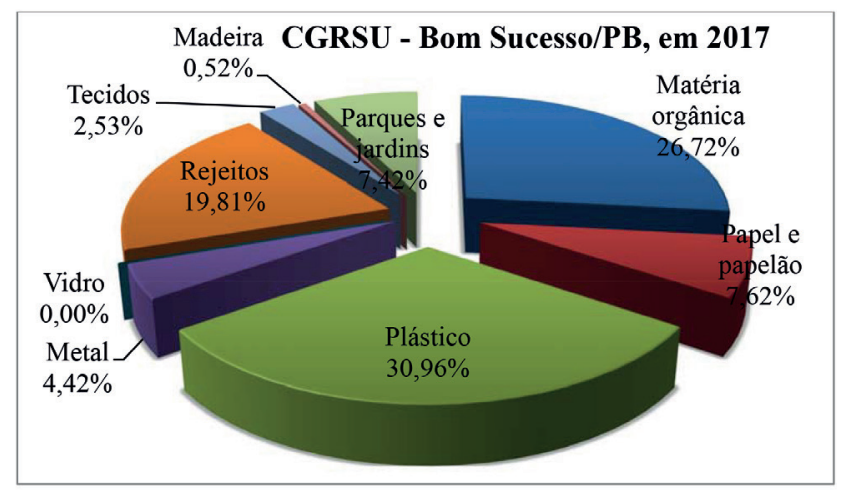

Fonte: Autores, 2020.

A gravimetria do município de Bom Sucesso-PB divergiu do que comumente se verifica em estudos desse tipo, pois o maior percentual geralmente está associado à fração de matéria orgânica (COSTA et al., 2012; REZENDE et al., 2013; SOUTO; RAIMAM; ALBINO, 2013; ARAÚJO et al., 2015; GALDINO; MARTINS, 2016).

Tal fato averiguado pode ser decorrente da cultura local e regional de segregação e acondicionamento nas residências de resíduos orgânicos e úmidos, os quais são posteriormente coletados nas residências por criadores de suínos e aves, que fazem emprego deste material para alimentação animal. 
Lunes (2017) apresenta um percentual de 45,40\% de matéria orgânica para o vazadouro de Pau dos Ferros-RN, o que demonstra predominância desse material. Entretanto, no município de Bom Sucesso-PB existe uma cultura de criação de suínos com restos de alimentos, desta forma reutilizando e reincorporando ao setor econômico, como forma de alimentação para tais animais.

O plástico presente no vazadouro divide-se em "plástico duro" e "plástico mole", como: garrafas PET, sacolas plásticas, embalagens de produtos de limpeza, descartáveis, entre outros. Esses materiais recicláveis são catados e revendidos pelo catador a terceiros.

Logo, a disposição inadequada dos resíduos sólidos urbanos pode ocasionar a tríplice poluição (ar, solo e água), uma vez que a degradação dos resíduos sólidos gera um líquido altamente poluidor, o chorume, que, se não for captado e tratado de forma adequada, pode provocar um desequilíbrio local (BAIRD; CANN, 2011; COSTA; ALFAIA; CAMPOS, 2019).

Estudo realizado por Lopes et al. (2016) mostra que o lixiviado (chorume) decorrente da disposição de resíduos no Lixão de Pau dos Ferros segue o fluxo natural do terreno para uma área de captação e tendo a possibilidade de ser desaguado no rio Apodi-Mossoró. Desse modo, a disposição dos resíduos no lixão pode acarretar a contaminação dessas áreas, alterando as propriedades físicas, químicas e biológicas do local e seu entorno, gerando prejuízos de ordem social, econômica e ambiental.

\subsection{ESTIMATIVA DO BIOGÁS}

Utilizando os dados obtidos em visita in loco, na gravimetria, e aplicando as equações e parâmetros previstos, e com o auxílio do programa Excel, pôdese obter os resultados referentes à estimativa de produção de gás metano $\left(\mathrm{CH}_{4}\right)$ para o vazadouro de Bom Sucesso-PB. Algumas considerações foram feitas para o preenchimento das equações, a saber:

$\checkmark$ Para a temperatura (T) da Eq. 4, utilizou-se a média das temperaturas máximas e mínimas do ano de 2017 . $\mathrm{T}=27,9^{\circ} \mathrm{C}$;

$\checkmark$ Na Eq. 3 todos os parâmetros A, B, C, D e E foram utilizados, com base na gravimetria da Figura 5, adotando-se seis casas decimais;

$\checkmark$ Para a Eq. 3 utilizou-se o valor de FCM de 0,4 (Tabela 1) por se tratar de um vazadouro;

$\checkmark$ Para a fração de RSD efetivamente depositados no vazadouro utilizouse o valor de $100 \%$, tendo em vista todos os RSU serem destinados ao vazadouro, não existindo outro local para destinação final; 
Conforme o Censo de 2010 (IBGE, 2017b), a população urbana era de 2.030 hab. de um total de 5.035 hab., o que significa dizer que 40,32\% correspondem à porcentagem da população urbana. Aplicando essa porcentagem na população estimada para 2017 (IBGE, 2017b) encontrou-se um valor de 2.005 habitantes na zona urbana da cidade;

$\checkmark$ A quantidade em $\mathrm{kg}$ de lixo coletado diariamente é de $1.000 \mathrm{~kg}$, logo em um ano, utilizando a população de 2.005 hab., temos uma taxa de RSD de 182,08 kg/hab./ano;

$\checkmark$ Massa específica do $\mathrm{CH}_{4}=0,740 \mathrm{~kg} / \mathrm{m}^{3}$.

Após as devidas considerações, e realizados os cálculos, chegou-se aos resultados apresentados na Tabela 3.

Tabela 3 - Parâmetros utilizados na determinação do biogás pelo método do IPCC

\begin{tabular}{c|c|c|c}
\hline Coeficiente & Símbolo & Unidade & Resultado \\
\hline $\begin{array}{c}\text { Paxa de geraçãão de RSD por } \\
\text { habitante/ano }\end{array}$ & Pop urb & Habitantes & 2005 \\
\hline $\begin{array}{c}\text { Fração de RSD efetivamente } \\
\text { depositada no vazadouro }\end{array}$ & RSDf & $\begin{array}{c}\mathrm{kg} \mathrm{RSD} / \text { habitante/ } \\
\text { ano }\end{array}$ & 182,08 \\
\hline Fator de correção do metano & FCM & Adimensionsional & 1 \\
\hline $\begin{array}{c}\text { Potencial de geração de metano } \\
\text { do lixo }\end{array}$ & $\mathrm{L}_{0}$ & $\mathrm{~kg} \mathrm{CH}_{4} / \mathrm{kg} \mathrm{RSD}$ & 0,33922149 \\
\hline $\begin{array}{c}\text { Carbono orgânico degradável } \\
\text { no RSD }\end{array}$ & $\mathrm{COD}$ & $\mathrm{kg} \mathrm{C} / \mathrm{kg} \mathrm{RSD}$ & 0,09484645 \\
\hline Fração de COD dissociada & $\mathrm{CODf}$ & $\mathrm{Adimensional}$ & 0,6706 \\
\hline Massa específica do metano & $\varrho \mathrm{CH}$ & $\mathrm{kg} / \mathrm{m}^{3}$ & 0,740 \\
\hline
\end{tabular}

Fonte: Autores, 2020.

Aplicando os dados da Tabela 3 na Eq. 1 temos:

$$
Q_{C H_{4}}=\frac{2005_{h a b} \times 182,08_{k g R S D / h a b * a n o} \times 1 \times 0,033922149_{\mathrm{kgCH}_{4} / \mathrm{kgRSD}}}{0,740_{\mathrm{kg} / \mathrm{m}^{3}}}
$$

Que resultou em uma produção de $16.731,87 \mathrm{~m}^{3} \mathrm{CH}_{4} /$ ano.

Em estudos realizados por Lunes (2017), a produção de metano chega a $1.303 .757,114 \mathrm{~m}^{3}$ /ano, um valor bem superior ao encontrado na pesquisa. Este fato pode ser justificado por Pau dos Ferros-RN possuir uma população mais elevada do que a de Bom Sucesso-PB, contribuindo assim para uma maior taxa de geração de RSU, e consequentemente para uma maior produção de biogás. 
A Tabela 4 apresenta um intervalo de porcentagem dos constituintes do biogás de resíduos sólidos urbanos. Para o presente estudo adotou-se a média dos intervalos para o metano, a amônia $\left(\mathrm{NH}_{3}\right)$ e o enxofre (ácido sulfídrico $\left.\mathrm{H}_{2} \mathrm{~S}\right), \operatorname{logo} 52,5 \%, 0,55 \%$ e $0,5 \%$, respectivamente.

Tabela 4 - Porcentagem dos constituintes encontrados no biogás de RSU

\begin{tabular}{cc}
\hline Componente & Porcentagem \\
\hline Metano & $45-60$ \\
Dióxido de carbono & $40-60$ \\
Nitrogênio & $2-5$ \\
Oxigênio & $0,1-1,0$ \\
Enxofre, mercaptanas & $0-1,0$ \\
Amônia & $0,1-1,0$ \\
Hidrogênio & $0-0,2$ \\
Monóxido de carbono & $0-0,2$ \\
Gases em menor concentração & $0,01-0,6$ \\
\hline
\end{tabular}

Fonte: Van Elk (2007).

De acordo com o percentual de metano e do valor encontrado na Eq.1, pode-se afirmar que a quantidade de biogás produzida no vazadouro de Bom Sucesso-PB, no ano de 2017, foi de 31.870,23 $\mathrm{m}^{3}$. De igual modo o volume produzido, relacionando os percentuais de $\mathrm{NH}_{3}$ e $\mathrm{H}_{2} \mathrm{~S}$, foi de $175,29 \mathrm{~m}^{3}$ e 159,35 $\mathrm{m}^{3}$, respectivamente.

Souza (2013) relata a importância quanto à captura e ao tratamento dos gases oriundos da decomposição dos resíduos orgânicos quando estes são compactados, uma vez que a degradação da matéria orgânica por meio da atividade microbiana promove o desprendimento de gases, e quando estes ficam confinados podem provocar cenários de explosão, colocando em risco a vida da população no entorno do vazadouro a céu aberto.

\section{CONSIDERAÇÕES FINAIS}

Ao analisar a logística de geração, coleta e destino final dos RSU de Bom Sucesso-PB, bem como os tipos de resíduos destinados ao vazadouro municipal, verificou-se que o município encontra-se dentre as cidades paraibanas que ainda destinam seus resíduos sólidos a vazadouros a céu aberto, sem segregação de recicláveis, sem impermeabilização do solo. Desse modo, pode ocorrer a tríplice poluição (ar, solo e água), considerando as características da área de estudo, 
em virtude da percolação do chorume e atmosférica pelos gases resultantes da decomposição microbiana, associada com a queima.

A composição gravimétrica do lixo possibilitou identificar uma predominância de material plástico, 30,6\%, seguido de MO com 26,72\%. Tal fato justifica-se pelos costumes locais dos habitantes de recolherem os restos alimentares para a criação de suínos.

A estimativa da geração de metano apontou valores pequenos, se comparados a grandes cidades, porém vale salientar que a geração do biogás contribui para o agravamento do aquecimento global, além da emissão de gases danosos à saúde pública. É necessário o encerramento das atividades do vazadouro imediatamente, bem como a aplicação de técnicas de remediação e bioengenharia buscando minimizar os impactos ambientais advindos da disposição inadequada dos resíduos sólidos urbanos.

\section{REFERÊNCIAS}

ABNT. ABNT NBR 8419: apresentação de projetos de aterros sanitários de resíduos sólidos urbanos. Rio de Janeiro, 1992.

ABRELPE. Panorama dos resíduos sólidos no Brasil 2018/2019. São Paulo: Abrelpe, 2019. Disponível em: https://www.migalhas.com.br/ arquivos/2020/1/492DD855EA0272_PanoramaAbrelpe_-2018_2019.pdf. Acesso em: 01 set. 2020.

ALKMIN, D. V; RIBEIRO JÚNIOR, L. U. Determinação da composição gravimétrica dos resíduos sólidos urbanos (RSU) do lixão do município de Maria da Fé, estado de Minas Gerais. Caminhos de Geografia, Uberlândia, v. 18, n. 61, p. 65-82, 2017.

ALMEIDA, F. A. et al. Cooperativas de catadores de resíduos e cadeias logísticas reversas: estudo de dois casos. Revista Eletrônica em Gestão, Educação e Tecnologia Ambiental, Santa Maria, v. 17, n. 17, p. 3376-3387, 2014.

ALVES, T. L. B. et al. Lixão de Campina Grande-PB versus Aterro Sanitário de Puxinanã: transferência de problema socioambiental. Polêmica, Rio de Janeiro, v. 12, n. 3, p. 460-468, 2013.

ARAÚJO, N. C. et al. Gravimetria e abordagem econômica dos resíduos sólidos urbanos do município de Barra de São Miguel - Paraíba. Revista Eletrônica em Gestão, Educação e Tecnologia Ambiental, Santa Maria, v. 19, n. 3, p. 67-72, 2015. 
BAIRD, C.; CANN, M. Química ambiental. 4. ed. Porto Alegre: Bookman, 2011. 844 p.

BRASIL, Lei n. 12.305, de 02 de agosto de 2010. Institui a Política Nacional de Resíduos Sólidos, altera a lei no 9.605, de 12 de fevereiro de 1998, e da outras providências. Brasília, DF: Presidência da República, [2010]. Disponível em: http://www.planalto.gov.br/ccivil_03/_ato2007-2010/2010/lei/112305.htm. Acesso em: 06 fev. 2019.

CAMPOS, H. K. T. Renda e evolução da geração per capita de resíduos sólidos no Brasil. Engenharia Sanitária e Ambiental, Rio de Janeiro, v. 17, n. 2, p. 171-180, 2012.

CAVALCANTE, S.; FRANCO, M. F. A. Profissão perigo: percepção de risco à saúde entre os catadores do Lixão do Jangurussu. Revista Subjetividade, Fortaleza, v. 3, n. 1, p. 211-231, 2007.

CNM. Observatório de lixões. Confederação Nacional de Municípios, Brasília, 2017. Disponível em: http://www.lixoes.cnm.org.br/. Acesso em: 03 fev. 2019.

CORDEIRO, C. J. D. et al. Prejuízos causados aos catadores que trabalham no lixão do município de Juazeiro do Norte - CE. Enciclopédia Biosfera, Goiânia, v. 8 , n. 15 , p. $2553-2562,2012$.

COSTA, A. M.; ALFAIA, R. G. S. M.; CAMPOS, J. C. Landfill leachate treatment in Brazil - an overview. Journal of Environmental Management, [S. l.], v. 232, p. 110-116, 2019.

COSTA, L. E. B. et al. Gravimétrica dos resíduos sólidos urbanos domiciliares e perfil socioeconômico no município de Salinas, Minas Gerais. Revista Iberoamericana de Ciências Ambientais, [S. l.], v. 3, n. 2, p. 73-90, 2012.

GALDINO, S. J.; MARTINS, C. H. Composição gravimétrica dos resíduos sólidos urbanos da coleta convencional de um município de pequeno porte. Tecnológica, Santa Cruz do Sul, v. 20, n. 1, p. 01-08, 2016.

GASQUES, A. C. F. Caracterização quantitativa e gravimétrica dos resíduos sólidos urbanos do município de Campo Mourão - PR. 2013. 55 f. Monografia (Trabalho de Conclusão de Curso em Engenharia Ambiental) Departamento de Engenharia Ambiental, Universidade Tecnológica Federal do Paraná, Campo Mourão, 2013. 
GBANIE, S. P. et al. Modelling landfill location using Geographic Information Systems (GIS) and Multi-Criteria Decision Analysis (MCDA): Case study Bo, Southern Sierra Leone. Applied Geography, [S. l.], v. 36, p. 3-12, 2013.

GODECKE, M. V.; NAIME, R. H.; FIGUEIREDO, J. A. S. O consumismo e a Geração de Resíduos Sólidos Urbanos no Brasil. Revista Eletrônica em Gestão, Educação e Tecnologia Ambiental, Santa Maria, v. 8, n. 8, p. 1700$1712,2012$.

IBGE. IBGE Cidades. IBGE, Rio de Janeiro, 2017. Disponível em: https:// cidades.ibge.gov.br/brasil/pb/bom-sucesso/panorama. Acesso em: 13 mar. 2017.

IBGE. Malha Municipal. IBGE, Rio de Janeiro, 2017. Disponível em: https:/ / www.ibge.gov.br/geociencias/organizacao-do-territorio/15774-malhas. html? =\&t=o-que-e. Acesso em: 01 set. 2020.

IBGE. IBGE Cidades. IBGE, Rio de Janeiro, 2020. Disponível em: https:// cidades.ibge.gov.br/brasil/pb/bom-sucesso/panorama. Acesso em: 01 set. 2020.

IPCC. Guidelines for national greenhouse gas inventories: reference manual (v. 3). Genebra: IPCC, 1996. Disponível em: https://www.ipcc-nggip.iges.or.jp/ public/gl/invs6.html. Acesso em: 15 jun. 2019.

LOPES, J. R. A. et al. Uso de imagens aéreas para detecção da contaminação do aterro comum de Pau dos Ferros-RN. In: SEMANA DAS ENGENHARIAS QUÍMICA, AMBIENTAL E SANITÁRIA DO OESTE POTIGUAR, 1., 2016, Pau dos Ferros. Anais [...]. Pau dos Ferros: UFERSA, 2016. p. 72-75.

LUNES, A. R. DA S. Proposta de técnicas de recuperação de área degradada para o lixão de Pau Dos Ferros/RN. 2017. 71 f. Monografia (Graduação Bacharelado Curso de Ciência e Tecnologia) - Departamento de Ciência e Tecnologia, Universidade Federal Rural do Semi-Árido, Pau dos Ferros, 2017.

LUNES, A. R. S. et al. Avaliação do lixão do município de Pau Dos Ferros - RN através dos métodos IQR e IQR-Valas. In: SEMANA DAS ENGENHARIAS QUÍMICA, AMBIENTAL E SANITÁRIA DO OESTE POTIGUAR, 1., 2016, Pau dos Ferros. Anais [...]. Pau dos Ferros: UFERSA, 2016. p. 84-87.

PESSIN, N; DE CONTO, S. M.; QUISSINI, C. S. Diagnóstico preliminar da geração de resíduos sólidos em sete municípios de pequeno porte da região do Vale do Caí, RS. In: SIMPÓSIO INTERNACIONAL DE QUALIDADE AMBIENTAL, 1., 2002, Porto Alegre. Anais [...]. Porto Alegre: Pontifícia Universidade Católica do Rio Grande do Sul, 2002. p. 47-54. 
REZENDE, J. H. et al. Composição gravimétrica e peso específico dos resíduos sólidos urbanos em Jaú (SP). Engenharia Sanitária e Ambiental, Rio de Janeiro, v. 18, n. 1, p. 1-8, 2013.

SALVADOR, F. L. R. Elaboração de um plano de recuperação de área degradada (PRAD) para um antigo lixão no município de Garopaba. 2012. 82 f. Monografia (Trabalho de Conclusão de Curso de Engenharia Sanitária e Ambiental) - Departamento de Engenharia Sanitária e Ambiental, Universidade Federal de Santa Catarina, Florianópolis, 2012.

SANTIAGO, L. S.; DIAS, S. M. F. Matriz de indicadores de sustentabilidade para a gestão de resíduos sólidos urbanos. Engenharia Sanitária e Ambiental, Rio de Janeiro, v. 17, n. 2, p. 203-212, 2012.

SANTOS, L. A. V. Gerenciamento de resíduos em torno da bacia hidrográfica do rio Apodi-Mossoró (RN). 2016. 95 f. Dissertação (Mestrado em Ciências Naturais) - Programa de Pós-Graduação em Ciências Naturais, Universidade do Estado do Rio Grande do Norte, Mossoró, 2016.

SENA, J. L. et al. Análise estratégica do plano de gerenciamento integrado de resíduos sólidos do município de Pedras de Fogo - Paraíba. Revista Ambiental, João Pessoa, v.1, n. 2, p. 21- 33, 2015.

SOUTO, F. B. D.; RAIMAM, M. P.; ALBINO, U. B. Resíduos sólidos urbanos em Porto De Moz -PA: problemas e oportunidades. Revista Geográfica Acadêmica, Boa Vista, v. 7, n. 2, p. 85-94, 2013.

SOUZA, A. E. Elaboração de um plano de recuperação de área degradada (PRAD) para o antigo lixão do Itacorubi, Florianópolis (SC). 2013. 128 f. Monografia (Trabalho de Concluso de Curso em Engenharia Sanitária e Ambiental) - Centro Tecnológico, Universidade Federal de Santa Catarina, Florianópolis, 2013.

VAN ELK, A. G. H. P. Mecanismo de desenvolvimento limpo aplicado a resíduos sólidos: redução de emissões na disposição final. Brasília, DF: MMA, 2007. 39 p. Disponível em: http:/ /www.mma.gov.br/estruturas/srhu_urbano/_ publicacao/125_publicacao12032009023918.pdf. Acesso em: 13 fev. 2019. 
